\title{
FORM MAKING AS A PROBLEM OF PHILOSOPHICAL AND
}

\section{AESTHETIC ANALYSIS}

\author{
Tatyana S. Bastrykina ${ }^{1}$ \\ Boris Yu. Belyakovsky ${ }^{2}$ \\ Yuri N. Kepa ${ }^{3}$
}

\begin{abstract}
The development of mass communication, the widespread computerization, as well as the development of technical forms of art, such as cinema, photography and advertising, and, in general, raising the level of civilization gives rise to a new way of perception and creativity, changes the spiritual culture, and influences the form making of mass consciousness. Under such conditions, the transformation of the sphere of cognition in general is obvious, allowing one to identify new aspects of scientific knowledge, as well as the specifics of new disciplines that arose at the junction of traditional scientific fields (semiotics, cybernetics, information theory, etc.), and requiring philosophical reflection. The boundaries of not only scientific
\end{abstract}

disciplines, but also of the types of art, become mobile. Montage, which was born as a technical tool of cinema, developed into the principle of montageability becoming as a result (like the two other favourite methods of postmodernism, collage and quotation) a thing, which determines everything for each mentality, including creative one. The relevance of the study is determined by the fact that in many works devoted to the study of the fashion phenomenon, sometimes there is an unconscious mixture of the concepts of "fashion" and "modelling of a suit," and, in particular, of their aesthetic functions, which does not allow us to fully identify the specifics of "clothing design" as a direction in designing. Moreover, until now, significant changes in the worldview of

1 Candidate of philosophical sciences, Professor, Higher School of Design, email: info@ ores.su, https://orcid.org/0000-0003-0093-1158

2 Associate Professor, Higher School of Design, email: russia@prescopus.com, https://orcid.org/0000-0002-7195-1087

3 Associate Professor, Higher School of Design, email: editor@ores.su, https://orcid.org/0000-0002-4053-6630. Russian State University of Tourism and Service, Moscow (FSBEI HE RSUTS) 
the XX century have not been reflected in the theory of fashion, in particular, in such its part as the shaping of a costume, and they can affect both the nature of the phenomenon itself and the fundamental principles in the field of costume design.

Keywords: design, philosophical and aesthetic analysis, analysis, information theory

\section{INTRODUCTION}

A person constantly encounters a variety of forms in everyday activities. The world around a person is always "shaped": architectural forms among which the person exists; natural forms, forms of things that saturate the interior of his or her apartment; the form of clothing that he or her wears, etc. Any reasonable human activity is shaped and the form, in essence, is only its trace in the outside world.

A form existing in human consciousness, is a means of cognition, and makes it possible to distinguish things from each other. An aesthetic attitude to the world is an emphasis on a form, which is why prose or poetic masterpieces are so difficult to perceive: because of the specificity of their form, they seem to hide the content from their

readers. The natural interest of mankind seems to be in the cognition of a form, in the ways of its specific manifestations and realization, in the ways of structuring the substantial diversity of the world, and in the interaction of a form with other forms.

The aesthetic problems of modern clothing design have not been sufficiently disclosed, although some works have touched upon significant aspects in connection with certain particular areas of clothing design. These are mainly foreign studies: articles by V. Morris, H. Dorsey in the International Herald Tribune, E. Thompson in the Guardian or J. Cox in Time, as well as Menkes S. "Issey Miyake: philosopher of fashion" in International Herald Tribune / 1988 / December 12 / P. 16; Dorsey H. "Lacroix taking couture back to Camargue roots". / International Herald Tribune / 1987 / Jule 7. / P. 8.

Certain aspects of new trends in the design of clothes are considered in publications devoted to the work of famous clothing designers (SaintLaurent Yves. "28 years of creativity", 1958-1986, Paris, 1986).

\section{METHODS}


The study used aesthetic and philosophical and art criticism methods. A historical approach to the object of study is also necessary in connection with the essence of the very historical being of such a phenomenon as fashion, design and for understanding the whole diversity of its components in the dynamics of development. The methods used in the work allowed with a greater degree of adequacy to show a complex picture of the existence of the object in the history of fashion and design.

\section{RESULTS AND DISCUSSION}

The main task of philosophy was to isolate the very concept of "form", to limit spatial forms from mental ones, as well as to study the relationship of form with content. Form as a general philosophical category is defined as a variety, a modification of content, a way of its existence and manifestation. The essence of the doctrine of displaying (and cognition) forms is to identify patterns, factors, and types of conformity or inconsistency of a form with its content.

Philosophy studies these problems throughout the history of human civilization. Form as an aesthetic category has always interested scientists.
We would like to indicate the development of the idea of form in the history of philosophy. [5]

Aristotle, the founder of one of the strongest rational traditions in European philosophy, distinguished between "forms that are without substance" and "forms that are in substance", thus dividing the spheres of being and thinking, but not building an insurmountable barrier between them. "Forms in substance" are spatial forms (translating Aristotle, Galileo calls them "bodies with a figure"). "Forms without substance" are what we would call "spiritual forms" today, that is, what our thinking operates with.

Cognition is feasible from sensory perception to deep knowledge of things. Sensory perception gives knowledge of an individual element, concrete experience; and knowledge of principles, or knowledge of the general and its causes is a higher level of knowledge. "With regard to any feeling, it is generally necessary to recognize that it is that which is capable of perceiving the forms of the sensed without its 
substance, just as wax takes the imprint of a ring without iron or gold". ${ }^{4}$

Aristotle singles out the first and second entelechy: simple and higher, and both depend on the state, on the disposition of a thing. The soul, for example, is the first entelechy of a material, natural body. Entelechy occurs where the essence, meaning and substance of substance are realized, where the general is embodied in the individual, the concrete, where the potential acquires reality. [3, 4]

Sensory knowledge is adequate and objective. Thanks to it, we perceive various properties of bodies, or special properties. Vision gives us the perception of colours, hearing - sounds, etc. But there are general properties: size, movement, peace, unity, number, etc. that are perceived by all the senses, and there is no any special organ for their perception.

A "figure" as a definition of a spatial "form" has been described by philosophers for several centuries. So, J. Locke believed that "a figure is a quality that is in all bodies, regardless of whether we perceive it or not". 5 Judgments, however, are possible due to the ability to turn sensory representations into the subject of thought.

I. Kant abandoned the concept of "spatial form." In his opinion, everything that is inherent in sensations serves as the initial elements of any knowledge about the world, and is actually the content of the world. However, content can only be an unorganized set of elements. Form is that which does not come from things and their effects on it, but from the activity of a subject itself. Therefore, the form of thinking is regularity, unity, something orderly supposing, organizing in cognition.

The concept of "spatial form" was emphasized by F. Hegel: "Space is only a certain form, that is, abstraction, namely abstraction of immediate appearance". 6 "The rest of the space figurations considered by geometry are further qualitative definitions of a certain spatial abstraction, surface, or some limited whole space. The difference between visible things is the difference in spatial forms... "7

\footnotetext{
${ }^{4}$ Aristotle "On a Soul" M., 1937, p. 421

5 J. Locke. Selected Philosophical Works, vol. 1, M., 1960, p. 160
}

\footnotetext{
${ }^{6}$ Hegel. The philosophy of nature. Op. Vol. 2, M.-L., 1934, p. 42

${ }^{7}$ Ibid, p. 47
} 
Further, the concept of "form of expression" will often be identified in philosophy with the concept of "spatial form". Such a substitution of concepts is based on a methodological contradiction: the characteristics of the knowledge content are mixed with knowledge of the content; the latter is presented as the former.

There were two dominant directions in defining the concepts of "content" and "form". The first approach coming from Hegel considers a form as an internal structure, organization of the content. The form in this case is the determining element, which orders an inert formless substance. Form gives a certainty to substance and directs its development from simple to complex. Thus, form appears to be a structure of content, and content without form simply does not exist. It turns out to be a certain composition of a thing or phenomenon, a combination of elements, properties, signs. It seems that the content here is presented as depleted, while the form takes on much more "content". The form essentially defines the content. [2]

Form and content in aesthetics are regarded as structures having an "internal" and "external" manifestation. Hence, there is a difference between the "internal form" and the "external form", the "internal" and the "external" content. This division was already expressed by Hegel: "Internal form" is the essence of the content expressing its law". 8 The difference between the "internal" and "external" forms is due to the material mediating the relationship between content and form. It turns out that the external form is determined by the material and the internal form is determined by the content. When the material changes, both its form and its content are changed. This principle of linkage is expressed in the following relationship: material - external form internal form - content.

The concept of "external form" is often identified with the appearance of a work of art, and appearance is still something other than form. The internal form is fixed in signs, images, and symbols and expresses spiritual information, absorbs specific poetic energy emitted by the core. The internal form is a form of expression of the figurative system, which is addressed to the imagination of a perceiving subject,

\footnotetext{
${ }^{8}$ See Hegel. Op. Vol. 2, p. 223
} 
and is fixed in the language of feeling. At this level, there are systems of relations between forms of signs-images, and the linkages that unite them into a form of unity and integrity are distinguished; the primacy of relations over elements is determined. The external form expresses volumetric-and-plastic, light-colour material, space, movement, living in time, all material substance extrapolated to a person, and the person himself organically "embedded" in this substance. National ethnic identity is included, which serves as the first perceived sign of the type of environment, the first signal that draws people's attention to the artistic sense of the environment structure. The unity of the internal and the external, the manifestation of the internal in the external characterize one of the aspects of the integrity of the product. But there is another side of integrity, which relates entirely to the external: this is compositional unity, the structural integrity of form. Any work should have a specific compositional purpose, a certain order of construction; mutual subordination of parts among themselves, their interdependence and conditionality, i.e. the main requirement of the composition is "unity of the parts of the work..$^{9}$ (See ch.III)

When analysing works of art, the need for the concept of "form" arises in connection with the need to introduce regularity into the subject of study, without which, by definition, scientific consideration is impossible. To make it possible to attribute the work to any era or region, it is often necessary to understand that the study of its external form and the determination of its structure play a huge role. The following items are highlighted:

1. The ways and means of the material existence of forms in art are paints, canvas, marble, word, sound, etc.

2. Means of material transformation of the properties of media artistic message (tools).

However, the form in the work is not a self-sufficient element. Both G. Wölfflin and the Russian formalists were criticized for the increased attention to it. The structure of the form is determined, in addition to the factors listed above, by the content factor. Indeed, very often exactly what we want to say determines

${ }^{9}$ F.M. Parmon, T.P. Kondratenko. Figure and graphic costume. M., Legprombytizdat, 1987, p. 189. 
the choice of means for expressing our message.

In this regard, the second approach seems interesting to us, considering the form as conditioned by the content and even existing as a way of its implementation. Upon this case, both the content and the form have their own structures and the structure of the form depends on the structure of the content.

So, the content of anything, a phenomenon, knowledge, etc. can be divided into a number of epistemological characteristics necessary in order to know the function of things, phenomena, knowledge, etc. These characteristics are as follows:

1. A qualitative characteristic includes a variety of its constituent elements, its differences from other objects;

2. The quantitative characteristic of the content of the image, knowledge is to determine the number of components, properties, and relationships. The determination of the qualitative diversity, the number of components and the system properties characterize its composition;

3. The structural characteristic of the content is central, because any thing as a system has a structure, or
889

rather, a multitude of internal and external structures that form its total structure. This concept can refer to a whole class of things or their states, and to unique objects and individual states;

4. The cognition of the content structures of a thing leads to the identification of properties that determine the functions, the arguments of which are these structures;

5. Content is also characterized semantically. Depending on whether the image is sensual or mental, two types of semantic relations are distinguished:

a) Objectivity, or objective meaning is inherent in the sensory image, their essence lies in the fact that not the state of his/her senses, but the reflected properties of objects are given in a direct experience of the subject;

b) Thought images have empirical and theoretical interpretations as varieties of the semantic relation.

The content and form in this case refer to the same object, or phenomenon, as its two sides. Upon that, the content appears as something invariant, conserved, and the form - as variations, varieties of this content. These basic characteristics represent, as it were, the dimension of the image content, its epistemological anatomy. 
Content needs ways of its existence, i.e. appropriate form, which are divided into external and internal. The external form in this classification is the "appearance", the visually perceived outline of an object (epistemologically, its first, superficial perception). The internal form is the structure of the subject. Any natural or artificial form has a complex structure, including elements of different levels: substantial, material, structural and composite, functional, decorative and others. Each of the elements, in turn, has its own structure different from structures of other forms. The predominance of a particular structure of elements in the form, the composition of structures and elements determine the processes of shaping and their regularity in different areas of human activity. [13.14]

There are stand out the following levels:

1. Space-time level;

2. Compositional level;

3. Style level;

The first two elements are the external form of the display; the third element is the internal form, since it is more directly related to the structure of the displayed object. It seems that this approach to the analysis of form is applicable both to spatial forms and to forms of thinking.

The rules of shaping, without doubts, apply to all forms of human art and practice. (In art, these are graphic, plastic, compositional, rhythmic and other means, a symbolic musical language, artistic techniques, etc.) [12]

Aesthetics and art history deal with ready-made art forms. Aesthetics deals with the "anatomy of form", the derivation of the general and the special; it differentiates various types and genres of art, explores the general laws of morphogenesis, and establishes the conditions under which the form becomes aesthetically significant, and, moreover, expresses and represents in the most accessible form the reflection of various cultural processes. Art studies determine the place of the sciences on the types of artistic creation in the field of human culture in general. The history of art studies dates back at least five centuries, but, in essence, theorization and high structurality begins in the mid19th century. The first works addressing the category of form in art (mainly on the basis of architecture) belong to the prominent art and cultural historian $\mathrm{J}$. Burkhardt. In his work "The History of the Renaissance in Italy" published in 
1867, Jacob Burkhardt differentiates and systematizes the concepts of form and composition tracing them in historical development. The main goal of $\mathrm{J}$. Burkhardt was to search for certain impulses that prevail in all art and those precedents that determine the work of individual masters. This postulate of Burkhardt was developed in the writings of his student G. Wölfflin, who sought to develop a strictly scientific methodology for the study of art: a systematic approach to the study of a work of art as an "objective fact", which should be understood, first of all, from itself. "The whole form and a complete analysis of the form are necessary in the visual arts for mastering the spiritual meaning". ${ }^{10}$

Style serves as a pure exponent of the spirit of the times, where a sense of form finds immediate satisfaction. Therefore, "an objective analysis of form," says Wölfflin, "is the only strictly scientific and accurate; and it is the means by which understanding of art became at a solid foundation of real documentary data". ${ }^{11}$

The psychological direction for studying the category of form was begun by A. Riegl (1858-1905), who opposed the concept by G. Semper, according to which the evolution of style and the development of art forms depend on the material, technique and purpose of the subject. According to Riegl, the cause of the evolution of art is "artistic will, or Kunstwollen", i.e. a thought which creates art. "Art in its evolution moves from a tactile, touching perception of an object to an optical one. In parallel, there is a movement from an objective view of the world to a subjective one. Style changes are only external manifestations of fundamental shifts in the spiritual structure of an era or people. And "artistic will" is that keystone beyond which no one researcher can look for. The work of art itself is only a reflection of Kunstwollen, its manifestation in the material, in the form. [11]

In many respects, this concept is based on the teachings of the psychophysical school of Fechner, Wundt, and Lipps, and is also associated with the loss at the end of the 19th and beginning of the 20th centuries of claims of any style for comprehensiveness and universal aesthetic significance. Alternating art directions at the end of the XIX - beginning of XX century:

\footnotetext{
${ }^{10}$ Welfin. Renaissance and Baroque, St. Petersburg, ${ }^{11}$ Ibid. 1913, pp. 75-78.
} 
impressionism, expressionism, cubism, etc., determined the dynamics of fashion and ideological positions of the creative environment. However, what is essentially important for artistic life is only partially important for other realizations of the cultural space. Confirmation of this is the complication, theorizing and, in a sense, the abstractness of style in philosophical and theory. The notions of style by Welfin, Focillon, or Riegl are key concepts among the categories of culture and actually define the internal essence, spirituality, and worldview of the era; they allow you to structure its specific historical manifestations. That is, in fact, style is an instrument of cognition and, thus, becomes a link to the problem of form that interests us as one of the main substances that mutually form a historical and cultural space. It was this aspect that was most adequately disclosed in the book of Henri Focillon, "The Life of Forms". Focillon refers to the study of the essence and design of form from the position of their relationship with the external surrounding world having all the multitude and variety of its manifestations. The main thing is to find the correlation between the dimensions of space from the scale of a person and up to the entering into the transcendental sphere having determined at the same time the ratio between natural forms and forms reproduced by art. "We are used to thinking that forms are a certain order and that this order is a manifestation of life. They are subject to the law of change, which constantly updates them and the law of styles, which ... tests, strengthens and breaks their ties". ${ }^{12}$ Nature creates forms; art transfers natural forms into its material, but as soon as natural forms fall into art, they acquire a new value, and generate new systems of meanings, and seek new contents for themselves.

Focillon's form is an abstract generalized concept, which in itself is difficult to define. Sometimes they confuse the concept of form with the concept of image, sign, with symbols imposed on it; they try to put a different meaning in the form. Indeed, one and the same form can retain its dimensions, but its qualities do not change depending on the material, techniques (moreover, a technique refers to skill and worldview), 
and processing tools: they are sources of diversity based on the diversity of human activities. Problems of changing forms are the problems of shaping; they are inextricably linked with a style that seeks to stabilize and coordinate them. The term "style" is determined primarily by the material and technology; Focillon has two different and even opposite meanings about it:

- Style is something absolute indicating the highest characteristic of art;

- Style is something changing, or variable.

We are interested in the second value, because in the second case, style is a system of forms that interact with each other and create a certain kind of harmony. Style are formal elements, which are signs, a dictionary, a set of forms that create a specific tool for shaping. Any interpretation of style should be based on two provisions:

- A simultaneous existence of several styles, in the same or in different types of art, is possible;

- Styles develop differently in different types of art;
However, the main feature in the interpretation is the presence of the relationship between style, technique and human nature. If a "state of style" as an external environment of forms is possible in general, "we can consider a work of art as a unique phenomenon in the ratio of these three values" only. ${ }^{13}$ Each style is directly dependent on the technique that gives it its originality. However, many types of art avoid dependence on technique within the framework of a uniform style.

A work of art also exists only as a form. It exists in space and material and also it exists in time, before or after other works. Its form making is not instantaneous: it is the result of a series of experiments, the result of social and artistic experience. The history of culture, therefore, is a conflict of prematureness, timeliness and lag. The problem of form in time is twofold: on the one hand, it is an internal problem that clarifies the position of art in the history of the development of forms, and on the other hand, it is an external problem that clarifies the relationship between this development area and other areas of human activity. Focillon

\footnotetext{
13 Там же, с.26
} 
examined the forms that exist in space, in substance, in consciousness, and in time. Form making in the aesthetics of Focillon is the interaction between space, substance, time, consciousness, and technique in the historical process of cognition of forms. $[8,9,10]$

This line was continued by $\mathrm{R}$. Arnheim. In the presentation by $\mathrm{R}$. Arnheim, the form is a polysemantic concept. It acts either as a tool of knowledge, or as a factor that is the main exponent of aesthetic, functional and other cognitive information in a product of art or design. Therefore, the form is considered in two aspects: firstly, it is interpreted as an operational unit of visual perception, including aesthetic, and secondly, it is considered as a source of patterns for development of a creative intention.

From all the above, we can conclude that, to a greater or lesser extent, all objects of the material and artistic culture of a given era and nation are subordinate to the style. Style organizes and draws up the subjectspatial environment surrounding a person. It leads to unity of objects of various purposes. It builds something integral, complete from the chaos of things. Due to the style, spontaneously evolving environment becomes a meaningful form. The thing therefore expresses not only its function, but also the "spirit" of the era that created it. The style is stable. The basis of style as a cultural phenomenon, as well as the general circle of manifestations of style in culture goes back to the epoch-making value manifestations of aesthetic relations of cultures. Manifestations of style in culture are diverse (style of language, speech, behaviour, thinking, and clothing) and in each era they have their own specific features. [1]

An ancient Egyptian, for example, created clothes for himself and the idea of order, the desire to build and organize the objective world with almost mathematical correctness, like in the fine arts of that time come from here, hence, there are the linear rigidity of the costume, its geometricity, constructive and compositional uniformity, accuracy of rhythms in the folds of the dress, and in the ornament.

The primitive cut of the Romanesque costume schematically repeats the volumes of the human body, as if hiding it in a case and creating massive, heavy volumes; the lines of the Gothic costume exactly follows all the curves of the figure finely completing it 
895

with pointed forms of hats, hoods and shoes that seem to have something in common with favourite motifs of architecture.

This influence of style-forming factors can be traced everywhere: in the calm and relaxed harmony of antique clothes, and in the architectonic division of the Renaissance costume, and in the lush layering and the picturesque game of textures and the moving masses of the Baroque costume. [6, 7]

\section{CONCLUSION}

Analysing the styles of different historical periods, we have been convinced that the features of shaping are subordinated to changes in the general style settings throughout the course of civilization. The era shaped the style, and fashion obeyed the laws of style. After analysing the theory of morphogenesis in the studies by $\mathrm{R}$. Arnheim, A. Focillon, and G. Wölfflin, we came to the conclusion that style is, in fact, an instrument of cognition and, thus, the connection with morphogenesis, which, along with style, influences the form making of historical and cultural space. The symbolic, iconic character of the spatial expression of the costume's forms is emphasized. We encounter in a suit, as well as in music associative with ideas about certain phenomena or objects. At the same time, it is not always possible to see a direct analogy with a subject of reality, but due to the various plastic, rhythmic and compositional combinations, the order and rhythm of their distribution, and certain emotional experiences or simply an emotional response can be caused, depending on the organization of its form. When developing a certain system of conventional signs, a suit always has a double function: as a sign which indicates belonging to society and as a sign reflecting the individual qualities of an individual: it can characterize a group with a certain ideology, and even express its moral and religious categories.

\section{REFERENCES}

Antipenko A.I. Sociocultural and normative-ecological aspect of the relationship between man and nature. Abstract of thesis for the degree of candidate of philosophical sciences. (Institute of Philosophy and Law, Academy of Sciences of the BSSR) Minsk, 1986.

Arnheim A. Art and visual perception. M., Progress, 1974. 
Bassin E. Ya., Krasov V. M. Social symbolism. Questions of philosophy. 1971, No. 10.

Berezovsky, Maximilian. Certainly a scandal: (about the "mass culture" of the West). M., Politizdat, 1986.

Beresneva V.Ya. On the concept of style-forming invariants in the history of clothing modelling. The problems of formalizing the means of artistic expression. (Style, corporate identity, styling, fashion). M., 1980.

Valkova N.V. The cultural and historical meaning and the professional basis of the work of an artist-designer. Abstract of thesis for the degree of candidate of art history. Moscow Higher Art and Industrial School "MVKhPU", Genisaretsky O.I. Methodological notes on the conceptual foundations of regional design. Regional problems of the living environment. Proceedings of All-Russian Research Institute of Technical Aesthetics "VNIITE". Series "Technical aesthetics." Issue 55. M., VNIITE, 1988.

Hoffman A.B. Fashion and people: a new theory of fashion and fashion behaviour. M., Science, 1994.

Zhuravskaya T.M. The role of a formal element in the propaedeutic design course. Abstract for the degree of candidate of art history. St. Petersburg, 1994.

Losev A.F. Symbols in the art. L., Science, Leningrad, Dep., 1985.

Mol A. Sociodynamics of culture. M., 1973.

Khan-Magomedov S.O. To the problem of national originality of the subject-andspatial environment. Aesthetic design issues. M., VNIITE, 1978.

Menkes S. Issey Miyake: philosopher of fashion. International Herald Tribune./ 1988/ December 12./ P. 16; Dorsey H. Lacroix taking couture back to Camargue roots. I International Herald Tribune./ 1987/ Jule 7./)

Turner V.W. Form of Simbolic action, T. H. Marshall. Sociology at the guroads and other essays. London. 1963 